\title{
Catalytic Recycling of \\ Ribonucleotide-Phosphorus by Different Iron Oxides: Mechanistic Insights from Time-Resolved Solution and Surface Speciation
}

\author{
AnNALEISE R. KLEIN ${ }^{1,2}$, SHARON E. BONE ${ }^{3}$, LudMILla \\ ARISTILDE ${ }^{1,2 *}$
}

${ }^{1}$ Department of Biological and Environmental Engineering, Cornell University, Ithaca, NY 14853, USA;

${ }^{2}$ Department of Civil and Environmetnal Engineering, Northwestern University, Evanston, IL 60208, USA;

${ }^{3}$ Stanford Synchrotron Radiation Light Source, SLAC National Accelerator Laboratory, Menlo Park, CA 94025, USA;

*Corresponding author: 1udmilla.aristilde@northwestern.edu

Field-scale data have long implicated iron $(\mathrm{Fe})$ (oxyhydr)oxide minerals in controlling phosphorus bioavailability by mediating strong adsorption of inorganic phosphate $\left(\mathrm{P}_{\mathrm{i}}\right)$ and organophosphate $\left(\mathrm{P}_{\mathrm{o}}\right)$ compounds [1] Beyond adsorption, these minerals can also mediate the catalytic hydrolysis of $\mathrm{P}_{0}$ biomolecules to release $\mathrm{P}_{\mathrm{i}}$ and organic by-products [2-4]. A mechanistic understanding of this abiotic turnover, however, is lacking. Previous phosphorus speciation was achieved mainly by measuring $\mathrm{P}_{\mathrm{i}}$ in solution colorimetrically and bulk total $\mathrm{P}$ analysis $[2,3]$. However, the accounting of both solution and surface-bound $\mathrm{P}_{i}$ and $\mathrm{P}_{\mathrm{o}}$ species is required [4]. Here we apply high-resolution liquid chromatography-mass spectrometry (LC-MS) and synchrotron $\mathrm{X}$-ray absorption near edge structure (XANES) spectroscopy to investigate the dephosphorylation of ribonucleotide compounds reacted with ferrihydrite (estimated stoichiometry, $\left.5 \mathrm{Fe}_{2} \mathrm{O}_{3} \cdot 9 \mathrm{H}_{2} \mathrm{O}\right)$, goethite $(\alpha-\mathrm{FeOOH})$, or hematite $\left(\alpha-\mathrm{Fe}_{2} \mathrm{O}_{3}\right)$. Using LC-MS, we obtained direct quantification of solution $\mathrm{P}_{\mathrm{o}}$ species and, with mass balance with solution $\mathrm{P}_{\mathrm{i}}$, amounts of surface-bound $\mathrm{P}_{0}$ and $\mathrm{P}_{\mathrm{i}}$ were determined. The relative abundance of the surface-bound species was also confirmed by XANES analysis. Time-resolved data, from 1 hour to 7 days, on the evolution of the $P_{o}$ and $P_{i}$ species provide new insights into the catalytic mechanisms of the different minerals (Fig 1).

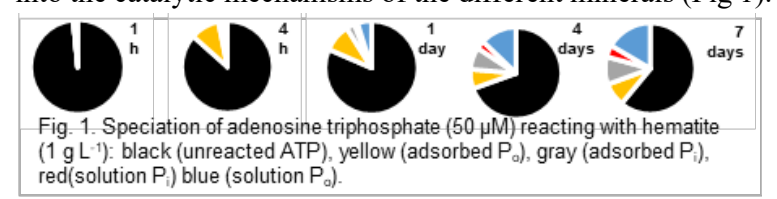

[1] Herndon, et al.. (2019), J. Geophys. Res. Biogeosci. 124, 227-246; [2] Baldwin et al. (1995), Environ. Sci. Technol. 29, 1706-1709. [3] Olsson, R. et al. (2010), Langmuir, 26, 18760-18770 [4] Klein et al. (2019), J. Colloid Interface Sci. 547, 171-182. 